\title{
ULUSAL TOPLUMUN VE ULUSAL KÜLTÜRÜN KURUCU ÖGELERİ
}

\author{
Prof. Dr. Özer OZANKAYA
}

Bu incelemenin amacı, bağımsız, demokratik, çağdaş bir toplum ve devlet olmanın yapısal koşullarını toplumbilimin verileriyle ortaya koymak, bunu yaparken, Atatürk Devrimleriyle kurulan Türkiye Cumhuriyeti'nin tüm uygar insanlık için örnek-koyucu (=precedent(etting) değerini belirtmektir.

Her şeyden önce toplumsal düzenin "kendiliğinden" biçimlenen bir şey olmadığını, bunun da ötesinde, insan ve toplum yaşamı için en büyük tehlikenin, en istenmez durumun "kendiliğindenlik" olduğunu belirtmek uygun olur. Bilinçli bir varlık olarak insana yaraşan, bireysel yaşamını olduğu gibi toplumsal yaşamını da bilinçle düzenlemeye çalışmasıdır. Nitekim bu yoldaki çabaların bir sonucu olan toplumsal bilimler ve öteki bilim dalları, toplu yaşamın oluşum ve işleyişindeki düzeni hem anlamaya çalışmakta, hem de elden gelen en büyük çoğunluğu, yine elden gelen en büyük gönence ulaştıracak biçimde nasıl düzenlenebileceğini araştırmaktadırlar.

Çağdaş toplum, ulusal toplumdur. Böyle bir toplumun temel kurucu ögeleri neler olabilir? Bu soruyu bir kaç ana kavram eșliğinde yanttlayabiliriz: A) Toplumsal yapt, B) Toplumsal kurum ve kurumlaşma süreci, C) Kültür, kültürel çağdaşlaşma ve yozlaşma durumları. - Çünkü çağdaş toplum, belli özelliklerde bir yapıya sahip, temel işlevleri yerine getirme biçimi kurumlaşmış, belli niteliklerde bir kültürü bulunan toplumdur. Öyleyse çağdaş toplumun kurucu ögeleri olarak bu yapı, kurum 've kültür olgularını incelememiz gerekiyor.

\section{A) TOPLUMSAL YAPI KAVRAMI}

Bilindiği gibi hemen her şeyin "yapı"sından söz ederiz. Ancak herhangi bir şeyin, örneğin bir masanın ya da bir bilgisayarın, ya da bir ailenin, okulun, .. vb. yapısından söz ederken onu oluşturan tüm 
ögeleri değil, üstlendiği asıl ișlevi neyse onu yerine getirmesi için zorunlu olan temel ögeleri ve bunlar arasındaki karşılıklı bağları anlatırız. Zaten yapı kavramı da böyle tanımlanmaktadır: her hangi bir şeyin üstlendiği işlevi yerine getirebilmesi bakımından zorunlu olan temel parçalar ve bunlar arasında yasalılık, düzenlilik gösteren karşılıklı bağlar ve ilișkiler.

Öyleyse toplumsal yapı da, töplu yaşamda yerine getirilmesi zorunlu olan başlıca işlevleri yerine getiren ana ögelerle bunlar arasında düzenlilik, zorunluluk gösteren, bu nedenle de göreli de olsa uyumlu bir bütünlük oluşturan karşılıklı bağlaıı ve ilişkileri anlatır.

Çağdaş bir toplumun varlığından sözedilebilmek için, bir insan topluluğunda şu temel işlevlerin kurumlaşmış olarak, yani etkin bir biçimde yerine getiriliyor olması gerekir:

1. Soyun (neslin) sürekliliğini sağlamā işlevi: aile kurumunca yerine getirilir.

2. Yeni kușakların ve genellikle toplum üyelerinin toplumun kültürüne, toplumsal çevreye hazırlanması işlevi: asıl olarak eğitim kurumunca yerine getirilir.

3. Toplum üyelerinin yaşama bir anlam vererek bağlanmalarını, yaşamı yaşanmaya değer saymalarını sağlama işlevi, dünya görüşlerini, üstün değerler (ultimate values, valeurs ultimes) dizgelerini dile getiren örgütlü kamuoyu kurumunca yerine getirilir.

4. Toplumda gerek duyulan türlü mal ve hizmetlerin üretilmesi ve dağıtılması işlevi, ekonomi kurumunca yerine getirilir.

5. Toplumun iç yaşamında özgürlük, güvenlik ve adaleti, dışarıya karşı bağımsızlığı sağlama işlevi, devlet ya da hükümet kurumunca yerine getirilir.

İște çağdaş ulusal toplumun yapısını oluşturan ana ögeler, aile, eğitim, örgütlü kamuoyu, ekonomi ve devlet kurumları olup, bunlar kendi aralarında birbirlerinin işlevlerini verimli olarak yerine getirmesini kolaylaştıracak uyumlu bir ilişki ve etkileşim içindedirler. Öyle ki, örneğin okulun çocuğa -ak dediğine aile kara demez; devletin adil, uygun ... saydığı şeyleri aile ya da ekonomi .. yersiz ya da haksız bulmaz; ekonominin meşruluk ölçüleri inanç ve ideolojinin, felsefi dizgelerin ve genellikle örgütlü kamuoyunun üstün değerleriyle çelişme içinde bulunmaz... 
Demek ki göreli bir uyum, çağdaş toplumun kurumlarının ağır basan, egemen olan özelliğidir. Gerçi toplum (yani société) olmayan, cemaat (örneğin ümmet, oymak, soy-topluluğu vb.) düzeyindeki toplu yașamda da böyle temel işlevlerin yine kurumlaşmıș ve uyumlu bir bütün olarak yerine getirildiği söylenebilir. Ancak çağdaș toplumda kurumların hem içindeki hem de aralarındaki uyum ve eşgüdüm, ileri düzeyde ișbölümüne dayalı, çoğulculuk yani türlülük eşliğinde ve gönüllü olarak benimsenen bir organik uyum ve eşgüdümdür; oysa "cemaat" düzeyinde işbölümü çok zayıf olduğundan, bireylik söz konusu değildir; her bir üye tıpkı tornadan çıkmış tahtalar gibi öbür üyeler neyse odur; farklılığa, girişimciliğe, yeniliğe ve yaratıcılığa olanak bırakmayan, zorlamaya dayalı mekanik bir dayanışmadır söz konusu olan. Bir de cemaat ortamının "kurum"ları, folklor düzeyinde olup etkinlik, verimlilik bakımından ulusal toplumunkilerden çok geridedir; çünkü ulusal toplum, bilim, sanat ve teknoloij düzeyine ulaşmış bir toplumsal yaşamı temsil eder. Folklor ise ne bilim, ne sanat ne de teknoloji sayılamaz; olsa olsa bunlar için hammadde sağlayabilir.

\section{B) TOPLUMSAL KURUM KAVRAMI}

Toplumsal yapının kurucu ögeleri, görüldüğü gibi her biri temel işlevlerden birini üstlenmiş kuı umlardır. Demek ki çağdaş toplumun temel işlevleri kurumlaşmış olarak yerine getirilmektedir. Yani kurumlaşmış olmak da çağdaş ulusal toplumun yapısal bir özelliğidir. Üstelik bu kurumlaşmışlığın bir yandan folklor düzeyinde değil, bilim, sanat, teknoloji düzeyinde bir kurumlaşma olduğunu, öte yandan bireyliğin gerçekleşmesini amaçlayan çoğulcu özellikte olduğunu da belirttiğimize göre, kurumlaşmanın nasıl gerçekleștiğini ana çizgileriyle bilmek, çağdaş ulusal toplumun gereklerini kavramak bakımından yararlı olacaktır.

$\mathrm{Bu}$ açıklamayı "kurum" kavramının tanımıyla başlatabiliriz: bir toplumsal kurum, üstlendiği islevin nasıl yerine gétirilmesi gerektiğini anlatan birbiriyle eşgüdülmüş düsünceler, değer ölçüleri, davranıs kuralları ile araçlar, gereçler gibi maddi ögelerden ve söz konusu düşünce ve değerlerin toplum üyelerinin zihinlerinde güçlü biçimde yer etmesi ve pekişmesi için oluşturulan rozetler, renkler, bayraklar, yıldönümü günleri. . gibi simgelerden kurulu bir bütünlüktür.

Görüldüğü gibi toplumsal kurumları meydana getiren asıl öge, onun içinde yer alan insanlar, araç-gereçler, yapılar.. vb. olmayıp, üst- 
lendiği işlevi nasıl yerine getirmesi gerektiğini anlatan düşünceler, değerler ve kurallardır; üyeler, araç-gereçler.. bu ana ögeye oranla çok geçicidirler. Örneğin "Türk siyasal kurumu" dediğimizde anlaşılması gereken şey, devlet başkanı, milletvekilleri, ya da başbakan, vb. olmayıp, "Eğemenliğin bağıtsız, koşulsuz ulusa ait olduğu, yurttaşın en bașta gelen hakkının ve en kutsal ödevinin her yurttaşla eşit olarak sahip bulunduğu oy hakkı olduğu, kamu yararı konusunda ne bir din, ne bir doktrin ne de herhangi bir kişisel otoritenin meşruluk dayanağı sayılamayacağı, tek meşruluk dayanağının kamu yararının her gün yeniden yeniye özgürce tartışılabilmesi ve belli aralıklarla genel oya başvurulması ilkesi olduğu.." vb. düşünceler, değer ölçüleri ve davranıș kurallarıdır. Bunun gibi "Türk aile kurumu" dediğimizde anlatmak istediğimiz şey, karı-koca ve çocuklardan kurulu somut birlikler olmayıp, bir erkekle bir kadının yaşamlarını birlikte sürdürmek ve topluma yeni üyeler kazandırmak istediklerinde bunu hangi ölçülere uyarak yapmaları gerektiğini anlatan düşünceler, değerler ve davranış kuralları toplamıdır: herkese açık resmi bir törenle kıyılan bir nikâha dayalı olması, kadının da erkekle eşit haklara sahip olarak yürütülecek bir birlik olması, kadının da kocası gibi eșit yurttaş konumunda bulunduğu, ergin (reşit) çağa gelen çocukların dinsel inançlarını seçme özgürlüğüne sahip olduğu .. ilkeleri.

\section{Başlıca Kurumlaşma Süreçleri}

Kurumlaşma, temel toplumsal işlevlerin nasıl yerine getirilmesi gerektiğini anlatan düșüncelerin, inançların, davranış kurallarının kafalarda belirginleşmesi, alışkanlıklara dönüşmesi ve böylece pekişmesi, sağlamca yerleşmesi demektir. Çağdaş ulusal toplum, böyle etkin, gelişkin bir kurumsal yapıyı, aşağıda belirtilen başlıca kurumlaştırma süreçleri yoluyla gerçekleştirmektedir.

A) Resmilik kazandırma: Söz konusu düşünceler, değerler, kurallar yazılı yasa, yönetmelik, tüzük.. hükümlerine dönüştürülerek, yıldönümlerinde kutlanarak, bayraklar, marşlar, renkler, rozetler, biçimler.. gibi simgelerle temsil edilerek... etkin, eşgüdümlü ve tutarlı olarak uygulanmaları sağlanır; denetimi kolaylaşır.

B) Varlığımı güvenceye alma: Toplum üyelerinin canlı bir ilgi duymalarını sağlama, kendilerine yönelik tehlikeleri gidermeğe çalışma, kısa süreli amaçlardan daha çok uzun-süreli amaçları gerçekleştirmeğe ağılık verme yollarıyla söz konusu ilkelerin varlığı güvenceye alınır, böylece kurumlaşmaları sağlanır. 
C) Değer özdeşmesi sağlama: Toplum üyelerinin söz konusu düşünce, değer ve davranış kurallarını, kendi başına izlenmeğe değer amaçlar olarak görmelerini, bunları yaşama anlam veren kișisel doyum kaynağı saymalarını sağlama.

Ç) Belirgin bir toplumsal tabana kavuşma: Söz konusu toplumsal ișlevin gereklerini kavramıș, etkin biçimde yerine getirebilecek özel bir ya da bir çok toplumsal kesimin oluștuı ulması: örneğin eğitim kurumunu ayakta tutup geliştirecek öğretmenler kadrosu, hukuk kurumunu yaşatıp ilerletecek hukukçular kadrosu, üniversite kavramını anlamış, özümlemiş bilim adamları kadrosu, ... bu kurumların özünü oluşturan düșünceleri, değer ëlçülerini ve davranış kurallarını etkin biçimde uygulamaya geçirerek kurumlaşmalarını, başka deyişle toplum üyelerinin beklenti ve alışkanlıklarına dönüşmelerini kolaylaştırirlar.

\section{C) KÜLTÜR, ÇAĞDAŞ KÜLTÜR VE KÜLTÜR YOZLAŞ- MASI KAVRAMLARI}

Böyle kurumlaşma aşamasına ulaşmış bir toplumsal yapı, “çağdaş ulusal kültür" sahibi bir toplumda olanaklıdır. Görüldüğü gibi "Ulusal toplum"un kurucu ögelerini belirleyebilmek için bir de "Kültür” kavramına ve kimi türevlerine bir ölçüde değinmek gerekiyor.

Kültür nedir? "Çağdaş ulusal kültür” ün.temel ögeleri ve başlıca özellikleri nelerdir? Ulusal kültürden yoksun toplulukların "Kültür bozulmasına ya da yozlaşması"na uğradıkları görülüyor. Bu ne demektir?

a) Kültür kavramının geçerli olarak tanımlanması, hem ulusal toplum olgusunu, hem de geri-kalmışlık olgusunu anlayıp açıklamak bakımından çok önemlidir. Kaldı ki herhangi bir açıklamanın geçerli olabilmesi için, başvurduğu kavramları açık, belirli tanımlara kavușturması zorunluluğu, bilimsel yöntemin temel kurallarından biridir.

Kültür kavıamının çok sayıda ve değișik tanımları olduğu -özellikle kimi insanbilimciler tarafından-söylenır ve böylece bu kavramın genellikle işe yarar, üzerinde birleșilebilir bir tanımının yapılamayacağı vurgulanmak istenir. Ben bu görüșe katılmıyorum. Çünkü çok sayıda denilen tanımlar içinde, aralarındaki farkın önemli olduğu gerçekte iki ana tanım kümesi vardır: bunlardan birincisi kültürü maddi ve manevi ögeleriyle bir bütün olarak gören ve her iki türlü ögentin kültürün 
niteliğini belirlemede çok önemli olduğunu kabul eden tanımlar kümesidir; ikinci tanım kümesi ise, çok ya da az açık bir biçimde kültürün yalnızca manevi ögelerden kurulu olduğu anlayışı üzerine dayalıdır; özellikle Türkiye'de bu kültür anlayıșinı savunanlar içinde kimileri de kültürün maddi ögelerinin "uygarlık" olarak adlandırılması gerektiğini, uygarlığın yani kültürün maddi ögelerinin başka toplumlardan alınabileceğini, ama bunun manevi kültür ögelerini etkilememesi gerektiğini ve bunun olanaklı olduğunu öne sürerler.

Bana göre bir ulusun kültürü, maddi ve manevi ögeleriyle uyumlu biı bütünkük oluşturur; bu uyumlu bütünlüğün olmadığı yerde ya ulusal toplum yoktur, ya da kültür yozlaşması yaşanmaktadır. "Uygarlık" kavramıyla "kültür" kavramı da aynı șeyi anlatır; uygarhı̆ı yalnızca maddi araçlardan kurulu saymak, bu kavram için hiç de yerinde, geçerli bir tanımlama olmaz. Kültürün maddi ögelerinin göz ardı edilmesi, sömürgeciliğin "kültür yozlaşması"nın baş nedeni olduğu gerçeğini görmeme, gözlerden kaçırma gibi olumsuz bir sonuca da yol açmaktadır.

$\mathrm{Bu}$ ön bilgi ve uyarılardan sonra; benimsediğim kültür tanımını sunayım: "Kültür, bir insan topluluğunun, doğal ve toplumsal çevresiyle etkileşim süreci içinde ürettiği maddi ve manevi ögelerin toplam bileşimine denir." Demek ki kültür, doğal ve toplumsal çevrenin türlü nesneleri ve bu çevre içindeki türlü insanlararası etkileşimleıi yönlendiren düşünceler, duygular, tutum ve davranışlar toplamıdır.

Kültürün maddi ögeleri, bir toplumun belli bir dönemdeki uygulayımisal (=teknolojik) ilerlemesini, üretim ve uygulayımdaki deneyim, beceri ve yeteneklerini yansitır. Özetle maddi kültür, insanın doğaya, topluma, hatta kendi kendisine egemen olma ölçüsünün göstergesidir. Eskiden ancak aylar süren yorucu bir yolculuktan sonra ulaşabildiği bir yere bugün $1 / 2$ saatte ulaşan insan, kendi fiziksel sınırlılıklarını -örneğin kanatlarının olmayıșı, vb.-- da aşmış olmaktadır.

Demek ki maddi kültür, insan çalıșmasının gerçekleştirdiği, ürettiği tüm nesneleri, bütünüyle uygulayımbilimi, araç ve gereçleri anlatır. Karasabana dayalı tarımın yaygın olduğu bir toplumun düzeni ile traktöre dayalı tarım yapan bir toplumun düzeni birbirinden çok farklidır.

Manevi kültür ise bu maddi kültür ile etkileşim içinde biçimlenen düşünceler, değer ölçüleri, davranış kuralları, gelenek-görenekler, 
dinsel, siyasal, fẻlsefi inançlar ...dan oluşan uyumlu bütünlüğe denir.

Olağan gelişimini (yani kendi iç dinamiği ile değişim ve gelişimini) engellemesiz sürdürebilen toplumlarda manevi kültür, biraz gecikmeyle de olsa, maddi kültürle uyum içine girer; onu destekleyici, onunla uyumlu yeni biçimler alır. Ulaşımı kağnıyà dayalı bir topluluğun manevi kültürü, kağnılla uyumlu değerler, davranışlar, kurallar ve inançlardan kurulu olduğu gibi, jet uçağına dayalı olan toplumun manevı kültürü de jete uyan, onu destekleyici nitelikteki inançlardan, kurallardan, sanatsal anlatımlardan... kuruludur.

$\mathrm{Ne}$ yazık ki az-gelişmiş denilen ve hemen tümü ya açık ve tam, ya da örtülü ve daha sınırlı bir ölçüde sömürgeleştirilmiş olan toplumlarda, bağımsız bir gelişmenin ve böylece maddi ve manevi ögeleriyle dengeli bif ulusal kültür oluşmasını sağlayacak atılım ve girişimlerin karşısına çıkarılan engeller, çoğu kez "Efendim, Batı'nın teknolojisini alalım; ama bizim manevi kültürümüz en iyisidir, ona dokunmayalım!" kılıfı içinde çıkarılmaktadır.

Türkiye'de de bu tutumu, üstelik ne yazık ki günümüze değin, benimseyenler olmuştur: Osmanlı devletinin yıkılışı yıllarında bile, örneğin Sebilürreşat dergisinde, günümüzde de "muhafazakâr" olduğunu söyleyen çevrelerde, bilimsel bir yanlışlık olan kültür - medeniyet ayrımı, hemen de aynı sözcüklerle yapılmış ve yapılmaktadır: "Bir ulusun kültürü başka, uygarlık ise başkadır. Uygarlığı dışardan alırsın, ama kültürünü (manevi kültürü kastediyorlar) korursun."

Bu düşüncede olanlaı, çağdaş uygarlı̆ı̆n, bilim uygarlığının, örneğin ünlü Fransız kimya bilgini Claude Bernard'ın bundan 150 yıl önce belirttiği gibi, "Laboratuara girerken yalnız pardösümüzü değil, inançlarımızı da kapının dışında bırakmamızı" gerektirdiğini, yaptığımız gözlemler inançlárımızı doğrulamıyorsa araştırma bulgularımıza gözümüzü kapamayı değil, söz konusu inançlarımızda değişiklik yapmamızı gerektirdiğini hiç duymak bile istememişlerdir. Çünkü örneğin Sebilürreşatçılar padişahlığın ve, halifeliğin sürmesinden yanaydılar, kadinın erkekle eșit yurttas haklarına sahip olmasına karșı olan dinsel hukukun, ezberci ve kesin bașeğici medrese eğitiminin yandaşıydılar. Bugün de "kültür - uygarlık ayrım" yapanların demokratik düzene ve bilim özgürlüğüne karşıt, laikliği sindirememiş kişi ve çevreler olduğu, bunların örneğin açık ya da örtülü biçimde padişahlık övgüsü yaptıkları görülmektedir. 


\section{Ziya Gökalp'in Bu Konudaki Yeri}

Osmanlı Devleti'nin son yirmi yılında düşünce yașamında etkili olmuş, Durkheim'cı okuldan Türk toplumbilimci Ziya Gökalp'in "kültür- uygarlık ayrımı" tartışmasında özel bir yeri vardır, diyebiliriz.

Ziya Gökalp, henüz Türk, Arap, Sırp, Rum, Laz, Kürt .. gibi çok etnik kümeli bir yapıya dayalı olan Osmanlı devletinin yaşamını sürdürebileceği sanısıyla, laik düșüncenin de daha filizlenmediği bir ortamda, Türkleşmek, İslamlaşmak, Medenileşmek sloganını ortaya attı. Bu slogan, sanki manevi kültürün değișmesine gerek kalmadan Batılılaşabilineceği sanısını yaymada kullanıldı: "Türk ulusundanım, İslam ümmetindenim, Batı uygarlığındanım!” sloganı, bugün bile Türk Devriminin demokratikleştirici, çağdaşlaştırıcı atılımlarına ve kurumlarına karşı olanların örtü olarak kullandıkları bir sav-sözdür.

Oysa doğrudan doğruya çağdaş "ulusçuluk", Batı toplumlarının son ikiyüzyil içinde oluşturduğu bir manevi kültür değeridir ve sanayi ve ticaret devrimlerinin, yani maddi kültürdeki köklü değişimlerin bir ürünüdür. Gerçi Ziya Gökalp, manevi kültürde köklü değişiklikleri birlikte getirmesi kaçınılmaz olan başka önerilerde de bulunmuştur, ama gericiler ve özgürlük karşıtları bunları bugün bile görmezlikten gelmektedirler. Örneğin: "Bir ülke ki camiinde türkçe ezan okunur köylü anlar mânâsını namazdaki duanın - Bir ülke ki minberinde türkçe kur'an okunur - büyük kü̧̧ük herkes bilir buyruğunu hudanın - ey Türk oğlu, işte senin orasıdır vatanın!" Ya da, "Arapça isteyen, Fizana gitsin Acemce isteyen Iran'a gitsin - Ki biz Türküz, bize türkçe gerektir Bunu anlamayan, cahil demektir" gibi düșünceleri göz ardı edilmektedir.

Türk Devrimi ise söz konusu ayrımın toplumbilimsel gerçekliğe aykırı olduğunun bilinciyle yapılmıs bir devrimdir. Bu devrimi "Batılılaşma" olarak nitelemek kanımca yanlıştır. Örneğin Atatürk'ün hemen hep çağdaşlaşma (muasırlaşma) nitelemesini kullandığını biliyoruz. İşte bu toplumbilimsel gerçekliğe uygunluğun bir belirişini de uygarlık - kültür ( o zaman kullanılan terimlerle söyleyecek olursak medeniyet ve hars) ayrımının yanlışlığını gören ve ona göre davranan bir devrim oluşunda buluyoruz. Geıçekten de Atatürk, daha Cumhuriyet'in ilk yıllarında bu ayrımın nasıl yanıltıcı olduğunu ve gericiliğe kılıf yapılabileceğini görerek bu kavramlara geçerli bir tanım getirmiştir:

"Uygarlı̆̆ın ne olduğunu başka başka tanımlayanlar vardır. Bence uygarllğı kültürden ayırmak güçtür ve gereksizdir. Bu görüşümü açıklamak için kültür ne demektir, tanımlayayım: 
- Bir insan toplumunun, a) devlet yaşaminda, $b$ ) düsünce yaşamında yani bilimde, toplumsal konularda ve güzel sanatlarda, c) ekonomik yaşamda, yani tartmda, sanatta, ticarette, kara, deniz ve hava ulaştırmacılığında yapabildiği şeylerin toplam bileşimidir.

Bir ulusun uygarlığı dendiği zaman, kültür adı altında saydığımız üc tür etkinliğin toplam bileşiminin dışında başka bir şey olamayacağını sanırım. ... Özetle, uygarlık kültürden başka bir şey değildir." (Prof. Afetinan, Atatürk Hakkinda Hatıralar ve Belgeler, T. İş Bankası Y., 1968, s. 278-279).

\section{Çağdaş kültür ve kültür bozulması kavramları}

Bu açıklamalardan sonra bir de çağdaş kültür ve kültür bozulması kavramları üzerinde durmamız gerekmektedir. Çünkü ulusal kültür, ancak çağdaș olursa var olabilir. Çağ dıșı ögelerle, dengesiz, yamalı bohça ya da altı kaval-üstü șişane durumundaki bir kültür ulusal değil, olsa olsa yoz kültür sayılmak gerekir. Kültür yozlaşmasının ya da bozulmasının baş nedeni de sömürgeciliktir.

Eğer Gerikalmışlık Toplumbiliminin gözlemi doğru ise bağımsız, yani yeraltı-yerüstü kaynaklarını ve ulusal pazarını özgürce, kendi yararına uygun biçimde değerlendirebilen topluluklar ulusal toplum olabiliyorlar ve çağdaş bir kültür geliştirebiliyorlar. Isşte bu çağdaş kültüre ulusal kültür diyebiliriz. Gerçekten de, çağdaş olarak nitelenebilen bir kültürde bulunduğu gözlemlenen temel özellikler, özgür ve bağımsız olma ile "ulusal" kültür sahibi olma arasında çok sıkı bağlar bulunduğunu göstermektedir:

a) Gelișkin bir yazuı dil sahibi olmak: bilimin, uygulayımın, sanatın en son gelişmelerini kendi dili ile anlatıma kavuşturabilen, terimlerini ve kavramlarını kendi sözcük kaynaklarından türetebilen, gelișkin bir dil sahibi olmak;

b) Evreni, doğayı ve insanı anlayıp açıklama yönünde özgürce laik felsefi dizgeler geliştirmek;

c) İleri teknoloji ve işbölümüne dayalı gelişkin bir ulusal ekonomiye sahip olmak;

c) Demokratik bir yönetim biçimine sahip olmak.

Bu temeller üzerinde yükselen bir kültürde, ayrica şu özelliklerin de bulunduğu görülür: 
d) İnsanın doğası konusunda iyimser bir anlayış: insanı "doğuștan günahkâr" saymayan, "ceza"yı öç almaya değil, istenmeyen davranışları önlemeye yönelik bir önlem olarak gören anlayış.

e) Zamanı, uzaklığı, doğal engelleri denetim altına alan bir bilim ve uygulayım (teknoloji) etkinliği: milyonlarca yıllık nesnelerin yaşını ölçebilmek, kaybolmuş dilleri ve yazıları çözüp (örneğin Sümer, Mısır, Aztec ...) insanlığın bilgisine ve hizmetine sunma, aya ulaşma... yeteneğinde olduğu gibi.

f) Çalışmayı ve üstlendiği işi en iyi biçimde yapmayı bir erdem, bir zevk, yaşamın anlamı olarak gören anlayış.

g) Bireýliğin de, toplumsal yaşamın da gereksinimlerini bilen ve bunları bağdaştıran bir insan ve toplum anlayışı.

h) Güzel sanatların, sağ-beğeninin (= estetik duygusu, zevk-i selim) insan ve toplum yaşamındaki önemli işlevini kavrayan bir anlayış.

i) Yerel kültürü ve folkloru, kültür ayrımcıllğına dönüştürmeden, ulusal kültür bileşimini zenginleştirici ögeler sayan, çünkü folklorun -yerel kültür egemén ölçüde folklor düzeyindedir- ne sanat, ne bilim, ne de uygulayım olmadığını, ancak bunlara ham madde sağlayabildiğini bilen bir anlayış.

Çağdaş kültürün bu tanıtıcı özelliklerini, ancak özgür ve bağımsız insan toplulukları gerçekleştirebilirler; sömürgecilik, sömürülen toplulukları özellikle böyle bir kültür geliştirmekten alıkoyucu bir etkendir ve günümüzde de, çok incelmiş yöntemler ve yollạrlạ etkinliğini daha da arttırmış olarak süregitmektedir.

Gerçekten de etkin bir sanayileşme, sağlıklı bir kentleşme, tarım dış1 öbür etkinliklerin -bilim, sanat, eğitim, sağlık, ulaşım, iletişim...gelişmesi, tarımın da en ileri yöntem ve uygulayımlarla çağdaş bir işletmecilik biçiminde yapılması, .. ancak özgür ve bağımsız toplumların gerçekleştirebileceği ereklerdir. Çünkü ulusal kaynakların özgürce kullanılabilmesini gerektirirler. İște bu özgürlüğe sahip olunduğu zamandır $\mathrm{ki}$, bir toplum manevi kültürünü de herhangi bir iç tutarsızlık ve uyumsuzluk sorunuyla ciddi ölçüde karşılaşmaksızın geliştirip çağdaşlaştırabilmektedir. Ulusal renk, ulusal biçem (üslup), kisacası ulusal kimlik de o zaman gerçekleşebilmektedir. 
Sömürgeciliğin ürünü olan kültür yozlaşması, sömürülen insan topluluğu kendi ortak yașamını özgürce düzenleme olanağını bulamadığı için ortaya çıkmaktadır: sömürgecilik, etkin, güçlü ve dürüst bir devlet yönetimine olanak bırakmadığı için, temel toplumsal işlevleri yerine getirmesi gerekli kurumlar arasinda da, bu kurumların kendi içinde de tutarlılık ve uyum kurulamamaktadır: okulun ak dediğine aile ya da işyeri kara demekte, bir okulun doğru bulduğu șey bir başka okulda yanlış diye sunulmakta, ortak yaşama belirgin ölçüde yön veren bir temel, örneğin demokrasi ideolojisi gibi pek büyük çoğunluğun içten katılımını elde edebilecek bir siyasal ve toplumsal değer ölçüleri dizgesi oluşamamaktadır. Tersine, örneğin "Ulusal egemenlik" ilkesine karşı, "Hâşâ! Allahın egemenliği!!" safsatası işlenebilmekte, çocuk yașta yüzbinlerce, milyonlarca bireyi bu karanlık içinde tutan odaklar dış ve iç sömürgecilerin işbirliği ile etkinlikte bulunabilmektedirler. O zaman "Her an, her yaptığından dolayı kamuya hesap vermek zorunluğunda olan yönetici" anlayışının yerine, "Ben ancak allaha hesap veririm!" diyen saltanatçı yönetici türeyebilmektedir; çünkü bir ülkenin en kolay böyle yöneticiler eliyle ve arac1lı̆̆yla sömürülebileceğini bilen yabancı sömürücüler, böyle yöneticilerin karar mevkilerine gelmesi için her türlü yasal-yasal olmayan yollardan etkilerde bulunmaktadırlar.

Sömürülen toplum böylece gerçek bir gelişmeden alıkonulmakta, asıl olarak hammadde üreticisi ve satıcısı, yapılmış mal alıcısı, kısacası çoban, rençber ve kol işçisi (amele) düzeyinde kalmaktadır. Ekonomik yaşamı bu olan bir toplumun manevi kültürünün düzeyi ne olabilir? Kuşkusuz folklor düzeyini aşamaz: ilkel düşünce yapısı, ilkel uygulayım, boş inançlar, gecekondu kentler ... İște kültür yozlaşması olgusunun gerçek nedeni sömürgecilik olduğu gibi, gerçek belirişi de budur.

Türkiye'de de 45 yıldanberi tanık olduğumuz, aynı süreçtir:

Gerçekten de Türkiye Cumhuriyeti'nin temelleri, çağdaş bir ulusal toplum olmak, çağdaş bir ulusal kültür geliştirmek için zorunlu olan özgür, bağımsız bir yönetim kurulması üzerinde yükseltildiği için, 15 yıl gibi kisa bir süre içinde bu yolda çok önemli sonuçlar elde edilebilmişti. Ama 2. Dünya Savaşı'ndan sonraki uluslararası ortam, Türkiye'yi Atatürk'ten yoksun yakalayınca, Marshall Planı yutturmacası altında Türkiye'ye sanayileşme iddiası terkettirilebildi. (Bunda, marksizm kılığı altında gerçekte Rus sömürgeciliği yapan Rusya'nın Türkiye'ye karşı açıkça dile getirdiği saldırgan politikasının da kolay- 
laştırıcı etkisi olduğunu, ayrıca Batı sömürgeciliğine karşı mücadele sanki marksistlerin işiymiş gibi bir görüntünün, her iki süper gücün çabasıyla, yaratılabilmiş olmasının da payı bulunduğunu eklemeliyim.) Özellikle 1950 sonrası siyasal iktidarlar Türkiye'nin asıl olarak hammadde üreticisi, yapılmıs mal alıcısı, ucuz işgücü deposu kalmasına yönelik bir ekonomi politikasını, bir yandan başta $\mathrm{ABD}$ olmak üzere sömürgeci ülkelerin dayatması sonucu, öte yandan bu politika halkı bilgisizlik karanlığında bırakacağı için kendilerine sürgit iktidarda kalma olanağı vereceği hevesiyle -1950 'de özgür seçimle yönetime gelen DP'nin, resmi yayın sözcüsü Zafer gazetesinde, elindeki iktidarı seçim yoluyla bırakmayı "enayilik" olarak nitelemekten çekinmediğini anımsamak yeter!-, uygulamaya koyulunca, kültür yozlaşmasının her türü aldı yürüdü.

Çünkü bir toplum asıl olarak hammadde çıkarımı ve al-satçılıkla ekonomik işlevini, yani toplumda gerek duyulan mal ve hizmetlerin üretimi ve dağıtımı işlevini yerine getiremez. Çağdaş kültürün ekonomi ögesi, asıl olarak sanayiye ve hizmetlere (=eğitim, bilim, sanat, sağlık ticaret, ulaşım, iletişim...) dayalıdır; tarım da çok gelişkin yöntemlerle, uzmanlaşmış birer işletme durumundaki çiftliklerde yapılır; ancak çalışma çağı nüfusunun en çok \% 15 kadarı tarım kesiminde çalışır. Ekonomi kurumu bu biçimde oluşamayan geri kalmış toplumlar, öbür temel toplumsal işlevlerini de özgürce ve uyumlu, tutarlı bir biçimde kurumlaştıramamaktadırlar. En başta sömürgeci, içerdeki işbirlikçileri ile elele, bir yandan devleti bağıml kılmakta, bir yandan da eğitim kurumlarını elden geldiği ölçüde çağdışı yöntemlere ve ögelere dayandırmakta, dünya görüşü kazandırma mekanizmalarını us-dışı, ortaçağcıl niteliklere boğmaktadırlar. Örneğin Türkiye'de her yıl yüzbinlerce Türk çocuğunun kafasina müziğin, kadın saçının görünmesinin haram olduğu, her bilginin Kur'anda bulunduğu, arap dil ve yazısının kutsal olduğu ve doğaüstü bir etki gücü bulunduğu ... gibi safsataların akıtılması, insanların şeyh, tarikat, türbe, yatır gibi yine ortaçağ artığı odakların etkisi altına girmek durumunda bırakılması, toplumun mezar-taşıyla övünmeye ve geçmişe gömülerek kaybedilmiş cenneti geçmişte aramaya yöneltilmesi ... gibi. Asıl kültür yozlaşması ve kültürel kimlikten yoksun kalınması bunlar iken, aynı iç ve dış sömürücüler bir yandan da Atatürk Devrimleriyle kurulmak istenen ve çok önemli ölçüde başarılan bağımsız devleti ve laik kamu yönetimini, çağın bilimi, sanatı ve uygulayımıyla uyumlu temel toplumsal kurumları kültür yozlaşması ya da Batı taklitçiliği olarak suçlamaktadırlar. Gerçek uya- 
nışın, gerçek ekonomik kalkınmanın bilimsel düşünüşle olabileceğini, bunun aynı zamanda ulusal kültür bilinci kazandıracağını bildikleri için, denetimleri altındaki eğitim ve iletişim kurumlarını bilim ve demokrasiye aykırı yönde beyin yıkama aıaçlarına dönüştürmekte, sömürgeciliğe en uygun ortam olan gericiliği desteklemektedirler. Yabancı sömürgeci, özel okulları, iletişim kanalları, bursları, vb.. ile bir yandạn da kendi dilini, dünya görüşünü, sanat anlayışını ... öğretip benimseterek çok sayıda yetenekli ve nitelikli genci beyin gö̧̧ü yoluyla kendi ülkesine çekerken, ülkede kalan aydın kesim de eğitimsiz, görgüsüz bırakılan geniş halk yığınlarından kopup ona yabancılaşmakta, halk-aydın kopukluğu ortaya çıkmaktadır.

İște ulusal toplumun kurucu öğeleri konusunu bu bağlamda ele almak gerekir kanısındayım. 